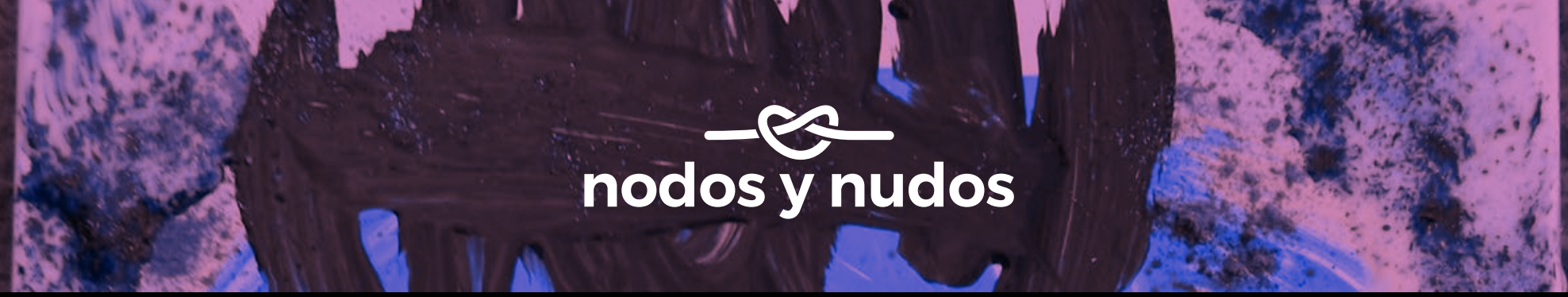

\title{
Rollos internacionales
}

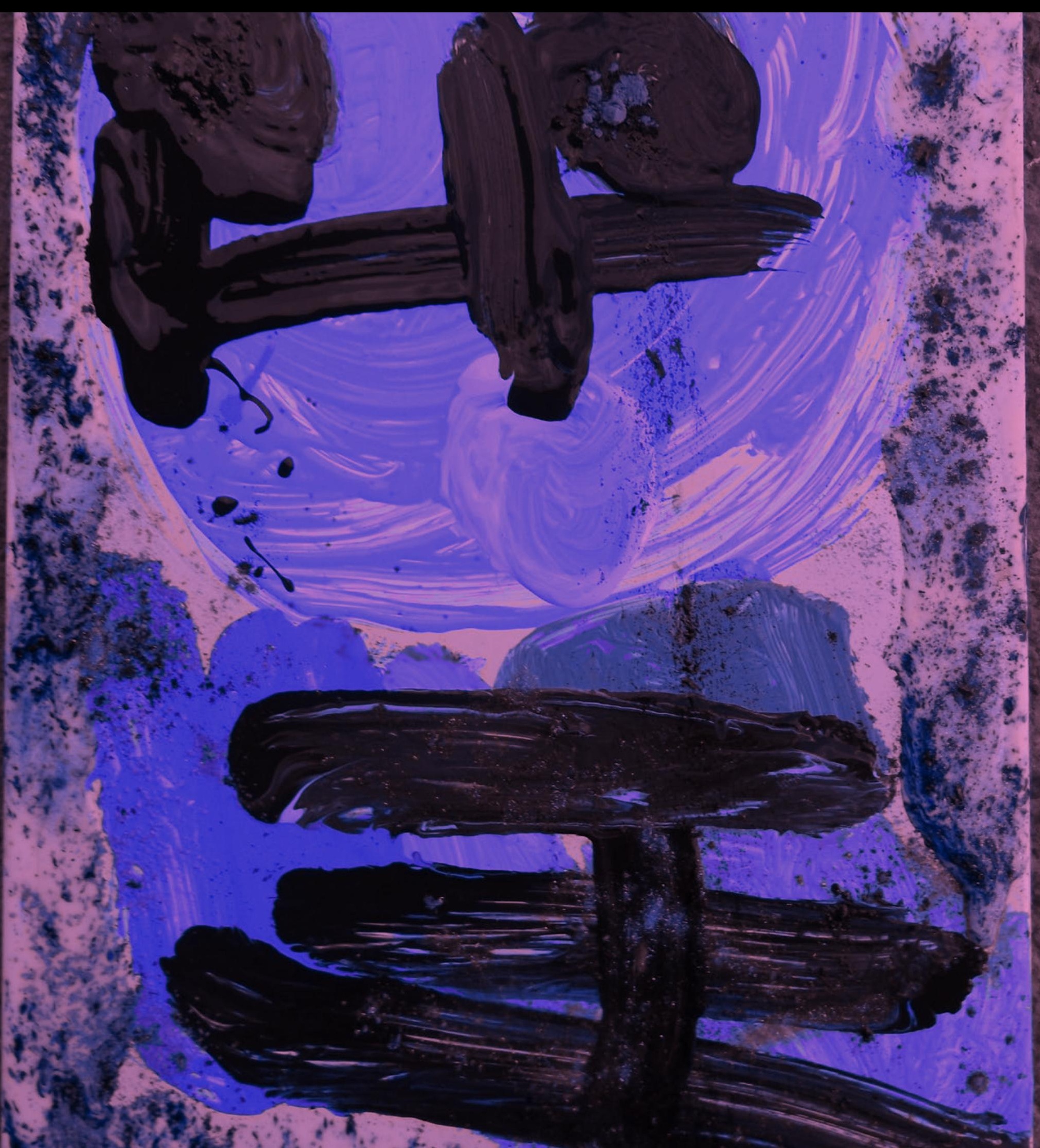




\section{Influencia de las ideas educativas en la formación de la cubanía}

Volumen 6 N. ${ }^{\circ} 47$

Influences of the Educational Ideas

in the Formation of the Essence of Being Cuban
Influência das idéias

educacionais na

formação da cubanía

Josefa Azel Jiménez*

Belkis Quintero Trujillo"*

Ángel Guido Navarro Otero"*

Fecha de recepción: 27-10-19

Fecha de aprobación: 04-12-19

\section{PARA CITAR ESTE ARTÍCULO}

Jiménez, J., Quintero Trujillo, B. y Navarro Otero, A. (2019). In-

fluencia de las ideas educativas en la formación de la cubanía. Nodos y Nudos, 6(47).

\footnotetext{
Doctora en Ciencias de la Educación. Máster en Educación Superior. Profesora titular del Departamento de Historia, de la Dirección de Historia y Marxismo-Leninismo de la Universidad Central Marta Abreu de Las Villas, Cuba. Correo electrónico: josefaa@uclv.edu.cu

* Máster en Ciencias de la Educación. Licenciada en Educación. Profesora asistente de la Facultad de Humanidades. Universidad Central Marta Abreu de Las Villas, Cuba. Correo electrónico: belquisq@uclv.edu.cu Doctor en Ciencias Pedagógicas. Máster en Ciencias de la Educación. Licenciado en Educación. Profesor titular. Director docente metodológico de la Universidad Central Marta Abreu de Las Villas, Cuba. Correo electrónico angelgm@ @uclv.cu
} 


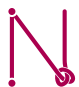

Volumen 6 N. ${ }^{\circ} 47$ julio - diciembre de 2019 ISSN: 0122-4328 ISSN-E: 2619-6069 pp. 25-34

\section{RESUMEN}

El presente artículo es parte de un resultado de una investigación cualitativa de corte históricoeducativa que tiene como objetivo revelar la importancia de las ideas educativas en el proceso de formación de la cubanía. En la formación de la cubanía desempeñaron un importante papel las ideas educativas. Desde finales del siglo XVIII y hasta finales del siglo XIX, se destacaron ilustres educadores cubanos que supieron inculcar el sentimiento de cubanía a sus alumnos, entre ellos se encuentran: Caballero, Varela, Luz, Mendive y Marti, que con sus ideas formaron los hombres cubanos, caracterizados por los valores de libertad e independencia contra el yugo colonial español; hombres capaces de construir una nación. Se arribó a las siguientes conclusiones: a partir de 1790, un sector de la burguesía nacional criticó duramente el sistema educativo hispanoescolástico y creó su ideario educativo. Las ideas educativas evolucionaron desde la llustración y el positivismo crítico, hasta llegar al avanzado pensamiento pedagógico de Martí. La aplicación de las ideas educativas cubanas tuvo como resultado la formación de la conciencia de la cubanía. Caballero, Varela, Luz, Mendive y Martí son los padres del pensamiento fundacional cubano.

Palabras claves: ideas educativas; educación; cubanía

\section{ABSTRACT}

This article is part of a scientific result of a qualitative research of a historical-educational nature that aims to reveal the importance of educational ideas in the process of formation of cubania. In the formation of the essence of being Cuban the educational ideas played an important role. From the end of the 18th century to the end of the 19th century, distinguished Cuban educators who knew how to instill the feeling of Cuban in their students stood out. Among them are: Caballero, Varela, Luz, Mendive and Marti, who with their ideas formed Cubans, characterized by the values of freedom and independence against the Spanish colonial yoke; men capable of building a nation. The following conclusions were reached: starting in 1790, a sector of the national bourgeoisie strongly criticized the Spanish-scholastic educational system and created its educational ideology. Educational ideas evolved from the Enlightenment and critical positivism, to reach Marti's advanced pedagogical thinking. The application of Cuban educational ideas resulted in the formation of the conscience of the essence of being Cuban. Caballero, Varela, Luz, Mendive and Marti are the fathers of Cuban foundational thought.

Keywords: educational ideas; education; Cuban

\section{RESUMO}

Este artigo é parte de um resultado de uma pesquisa qualitativa de caráter histórico-educacional que visa revelar a importância das idéias educacionais no processo de formação da cubanía. As idéias educacionais tiveram um papel importante na formação de Cuba. Do final do século XVIII ao final do século xIX, destacaram-se educadores cubanos que sabiam instilar o sentimento de cubano em seus alunos, entre eles: Caballero, Varela, Luz, Mendive e Martí, que com suas idéias formaram homens Cubanos, caracterizados pelos valores de liberdade e independência contra 0 jugo colonial espanhol; homens capazes de construir uma nação. As seguintes conclusões foram alcançadas: a partir de 1790, um setor da burguesia nacional criticou fortemente o sistema educacional escolástico-espanhol e criou sua ideologia educacional. As idéias educacionais evoluíram do lluminismo e do positivismo crítico para o pensamento pedagógico avançado de Marti. A aplicação das idéias educacionais cubanas resultou na formação da consciência cubana. Caballero, Varela, Luz, Mendive e Martí são os pais do pensamento fundador cubano.

Palavras chave: idéias educacionais; educação; Cuba 


\section{Introducción}

A partir del siglo XVI, se conformó lentamente la sociedad colonial criolla hasta llegar a consolidarse en el siglo XVIII. Después de la toma de La Habana por los ingleses (1762-1763), España aplicó la política del despotismo ilustrado. Consecuente con esa política llegaron a Cuba gobernantes más ilustrados y capaces, lo que unido a otras circunstancias históricas externas posibilitaron la apertura para el progreso económico.

Importantes transformaciones en la economía y la sociedad se desarrollaron a partir del último tercio de esa centuria. Cuba supo aprovechar la coyuntura internacional favorable para desarrollar su producción azucarera y cafetalera. Surgió así, el sistema de la plantación esclavista y, por ende, la existencia de una sociedad esclavista en la Isla. La esclavitud se generalizó a toda la actividad productiva y propició que toda la población estuviera comprometida con ella, en mayor o menor medida.

Al mismo tiempo, los hechos internacionales influyeron positivamente en el plano de las ideas politicas y en el ambiente cultural de la Isla. El proceso se consolidó a fines del siglo XVIII e inicios del XIX. Las ideas iniciaron el camino hacia la formación e integración nacional.

En el proceso de formación de la cubanía, definida por Torres-Cuevas $(2017$, p. 1) como "la vocación de ser cubano", las ideas educativas desempeñaron un importante papel.

En correspondencia con este postulado, el presente artículo es parte de un resultado científico de una investigación cualitativa de corte histórico-educativa que tiene como objetivo revelar la importancia de las ideas educativas en el proceso de formación de la cubanía.

\section{Desarrollo}

Precisamente, desde 1790 hasta 1820 comenzó un naciente sentimiento de nacionalidad condicionado por diversos factores culturales, sociales y económicos externos e internos, dados por el acelerado crecimiento económico que provocó el sistema de plantación esclavista en el cultivo de la caña y la producción de azúcar en los ingenios.
El auge de la economía azucarera perfiló de forma definitiva a la burguesía esclavista criolla que, al adquirir conciencia de su papel, se transformó en la primera clase social plenamente estructurada y en el primer núcleo dirigente de la nacionalidad. En estos años surgió un cerrado y brillante grupo de hombres de pensamiento conocido como la Generación del 92 o la llustración Reformista Cubana. Ellos constituyeron la primera expresión de un quehacer político, intelectual, científico y económico cubano.

A fines del siglo XVIII e inicios del XIX, las figuras políticas ilustradas más importantes propiciaron la creación de instituciones para impulsar el desarrollo de la cultura, y en especial de la educación. Se destacan el Seminario San Carlos y San Ambrosio (1773), la Sociedad Económica de Amigos del País (1793) y el Real Consulado de Agricultura, Industria y Comercio (1795). Estas instituciones fueron monopolizadas por el sector cubano y utilizadas a favor del desarrollo de la cultura de la burguesía esclavista criolla.

Alrededor de 1802, empezó a desarrollarse otra corriente en la llustración Reformista Cubana como resultado de los constantes cambios en los gobiernos de España. Se produjo una apertura hacia las ideas liberales que entraron en la Isla con los gobernantes y las figuras de la Iglesia: Don Luis de las Casas y el obispo Juan José Díaz de Espada y Fernández de Landa. Ambos representaron el proyecto liberal que ofrecieron posibilidades de desarrollo en el plano de la cultura y la sociedad. La burguesía criolla llegó a participar en el gobierno de la Isla.

Se nuclearon en las instituciones de avanzada de aquel entonces: la Sociedad Económica de Amigos del País, el Papel Periódico de la Havana y el Seminario de San Carlos y San Ambrosio. La actividad del grupo criollo se dirigía más a la esfera social y a la del pensamiento que a la económica. Consciente de la necesidad histórica del cambio político, social y cultural, el grupo abandonó los principios de la cultura hispana oficial y comenzó a preparar un pensamiento propio.

Este sector de la burguesía criolla se adscribió a la llustración con un sello muy original. Fue capaz de crear, durante un proceso histórico complejo y contradictorio, un pensamiento filosófico como punto de orientación de la cultura cubana en ciernes. En el Papel Periódico de la Havana, publicaron artículos 
que criticaban la educación y las ideas educativas imperantes. Comenzaron a proponer nuevas ideas para aportarle otra orientación a la educación y también promocionaron nuevos métodos pedagógicos.

Así, conformó su proyecto cultural en el que la educación ocupó un lugar destacado, ya que esta tiene como objetivo la formación del hombre con una marcada orientación ideológica. Con la finalidad de sustentarlo, fundó la Sociedad Económica Amigos del País en la que se distinguió su Sección de Educación, creada en 1816.

La burguesía cubana consideró necesaria la inclusión de la educación y la escuela como institución dentro de su gran proyecto cultural para lograr afianzar de forma definitiva, el sentimiento de cubanía en la conciencia de las nuevas generaciones. De ese modo, crearon su propio camino en materia educacional y abandonaron la copia acrítica de los modelos importados.

A partir de la fundación de la Sociedad Económica de Amigos del País, se comenzó a realizar una labor en aras de la educación. Su primera tarea consistió en elevar el nivel de instrucción de la población e incorporar mejoras en el sistema de enseñanza. Para ello, se encargaron de investigar la problemática existente y se constató el estado lamentable de la educación en las escuelas de primeras letras establecidas en La Habana. Al padre José Agustín Caballero, se le encomendó la redacción de Las Ordenanzas para estas escuelas.

El documento normaba el trabajo que realizarian los maestros en la escuela elemental para lograr un mayor aprovechamiento académico de los estudiantes. Planteaba exigencias de gran valor educativo en las relaciones maestro-alumno y la inspección en las escuelas, Ilamadas Cuerpo de Curadores. Esas exigencias sentaron bases en la actividad educacional cubana al permitir que el nivel de enseñanza más importante para la vida se desarrollara por vías científicas.

El padre Caballero, profesor del Seminario San Carlos, criticó la enseñanza oficial arcaica; se enfrentó directamente al escolasticismo imperante, tanto en la enseñanza como en el pensar y el actuar. Propuso una reforma de los estudios universitarios en Cuba, implantó la experimentación en la enseñanza de la física. Introdujo un sentimiento diferenciador del criollo a la racionalidad del pensamiento moderno, sentó las bases de una conciencia en sí de lo cubano. "Determinó el fin de la educación con la formación de hombres activos y capaces que sirvieran a la patria" (Pérez, 2007, p. 87).

Según sus concepciones, la enseñanza debía abrirse al conocimiento universal, pero adaptada a las circunstancias que caracterizan el suelo cubano, pues consideraba que el mejor plan de estudios para un centro escolar es aquel sustentado en este principio. Fue partidario de la enseñanza en lengua española (como primer paso para la formación de la cultura y la nacionalidad cubana), ya que el idioma como instrumento de socialización entre los hombres tiene una misión socializadora y nacionalizante.

Asimismo, planteó un conjunto de necesidades sociales y educativas, tales como: educación para la mujer, la beneficencia pública y la formación ética de los alumnos. Al escribir su Filosofía electiva, demostraba una nueva actitud intelectual: "El cambio de mentalidad y la autoevaluación de las capacidades propias del criollo para contribuir a la formación de esa nueva generación que tuviera ideas propias" (Torres-Cuevas y Loyola, 2006, p. 130).

José Agustín Caballero y Rodríguez fue el promotor de los cambios culturales y ha sido considerado "el padre de la filosofía cubana" al combatir la filosofía escolástica decadente y los anticuados métodos de enseñanza de la iglesia católica.

No obstante, el proyecto educativo escolástico-hispano predominante hasta fines del siglo XVIII, se mantuvo inalterable en sus postulados teóricos básicos. Poco tiempo después, el Gobierno colonial decidió su reestructuración como consecuencia de los cambios en las condiciones históricas imperantes, pero, sobre todo, por la aguda confrontación con el proyecto educativo cubano que se desarrollaba paralelamente.

A principios del siglo XIX, bajo la dirección del obispo Juan José Díaz de Espada y Fernández de Landa, el Seminario San Carlos mostró su verdadero avance con la introducción de nuevas ideas filosóficas y nuevos métodos de enseñanza. Se convirtió en un foco de luz de la cultura cubana en el momento que comenzaba a formarse una conciencia nacional, es decir, el sentimiento de la cubanía. Su prestigio trascendió los marcos isleños para convertirse en uno 
de los primeros colegios de su clase en las colonias hispanoamericanas.

Su singularidad consistió en que siendo un centro donde se cursaban carreras eclesiásticas y no eclesiásticas, alli se formaron los principales hombres de ciencias y de letras de una generación decisiva en los primeros años del siglo xIx y a pesar de que su fundación estuvo ligada a la Iglesia católica y a la Corona, en su recinto se escucharon voces de crítica a los males sociales de la época, así como de reconocimiento a los derechos civiles del hombre.

Félix Varela y Morales, precursor de la independencia de Cuba, fue profesor de Filosofía y de Constitución en el Seminario San Carlos en donde luchó contra los métodos escolásticos en la educación. Criticó el sistema educacional de su época y se preocupó por elevar la calidad de la enseñanza.

Argumentó y empleó el método explicativo, mejoró el aprendizaje de la gramática, estableció la enseñanza de la física y la química basadas en la observación y la experimentación; combatió la memorización estéril, así como impartió las clases en lengua materna y no en latín como se acostumbraba. Con estos métodos y prácticas de enseñanza influyó en sus alumnos en la formación del sentimiento de la cubanía. En resumen, causó una revolución filosófica que repercutió en la enseñanza, ya que puso la razón al servicio de la educación.

Sus aportes a la educación no se limitaron al plano instructivo, sino que estuvieron dirigidos a la formación de ciudadanos de profundas convicciones, humanismo creador y comprometido. Comprendía la necesidad de formar una juventud que pensara por sí misma, ajena a esquemas y dogmas. La acción de los cubanos debía estar en sus acciones intelectuales o políticas, pero sobre todo en la formación del hombre, en la educación del niño y del joven, de ambos sexos, en fin, para todos. Se considera, por tanto, precursor del alcance social de la educación al introducir el concepto de educación popular. (Azel, 2018, p. 13)

Varela fue el primero que habló de independencia a sus alumnos en las clases de Constitución, aunque estaba consciente de que era un ideal inalcanzable. De ahí que se dedicara a formar hombres de conciencia. Por eso, se coincide con el siguiente criterio: "El aula debe ser un escenario de puertas abiertas para analizar la relación entre saber, cultura y política que, en lo sustancial, tal como lo sostiene Freire, es una apuesta por la educación como práctica de la libertad" (Sánchez, 2019, p. 100). En su afán de colaborar en la formación de la nueva conciencia social cubana, escribió las Cartas a Elpidio (1835-1836), especie de obra educativa no convencional dirigida a la juventud cubana, a la que calificó como la dulce esperanza de la patria.

En la ideología emancipadora de Varela se encuentran el origen y las bases más sólidas del pensamiento cubano. Desde las páginas del periódico El Habanero, planteó sin vacilación su ideario independentista. Al respecto, escribia: "Cuba debe ser tan isla en lo político como lo está en la naturaleza; es decir, independiente y soberana y esa independencia debe alcanzarse sin la intervención de potencia extranjera alguna" (Varela, 1935, p. 37), lo que demuestra el desarrollo de una conciencia cubana no porque existiese la nación, sino por la aspiración a crearla.

Lo fundamental para el presbitero era la creación de la nación, concebida como el núcleo unitario de un pueblo con rasgos comunes dentro de sí mismo y diferentes a los de otros países; buscó los elementos que permitieran la creación de una autoconciencia nacional. Fue el primero en reconocer que el concepto de patria debia tomarse para unificar la acción política cubana.

José Martí, el Apóstol de la independencia de Cuba, dijo: "La Revolución independentista es el resultado de un siglo de labor patriótica" (Martí, 1963, p. 142), pues la enseñanza patriótica de Varela, valorado por Martí como el santo cubano, había irradiado a toda la sociedad cubana.

Félix Varela, verdadero padre de la cultura cubana, el que nos enseñó a pensar, que se enfrentó al dogmatismo religioso es el iniciador de la ideología independentista. De ahí que sea considerado como piedra fundacional de la nacionalidad cubana. Por lo avanzado de su pensamiento, teniendo en cuenta las condiciones de Cuba en la época en que vivió y su condición de sacerdote, Varela fue, sin dudas, un precursor. (Azel y Pérez, 2018, p. 6)

José Antonio Saco, uno de sus discípulos más brillantes, lo sustituyó en la cátedra de Filosofía del Seminario y aplicó sus principios pedagógicos. Comprendió que no era posible acometer el desarrollo del 
país sin propagar la instrucción popular. Defendió el criterio relacionado con la entrada de un niño a la escuela, ya que no debía depender de la situación socioeconómica de sus padres.

Exigió, como vocero del Reformismo en su segunda etapa, escuelas para todos al considerar a la educación como un medio para mejorar las condiciones económicas del país. En su Informe contra la vagancia en Cuba, premiado por la Sociedad Económica Amigos del País en 1831, clamó por la enseñanza gratuita para el pueblo.

Saco fue la figura política de mayor alcance teórico del movimiento reformista de los años 1830. Caracterizado como un agudo crítico del sistema colonial, de gran sentido nacionalista y el más opositor al movimiento anexionista. Defendió la existencia real de la nacionalidad cubana cuando se enfrentó a esta corriente política, pues estaba convencido de que sería una absorción.

Digno discípulo de Caballero y Varela, fue José de la Luz y Caballero, el maestro por excelencia. Relevó a Saco en el Seminario San Carlos en 1824. A partir de ese momento comenzó a actuar en la vida cubana, pero se mantuvo escéptico ante el ideal independentista. Planteaba a sus discípulos cautela, convencido de que hasta tanto los cubanos no tuvieran la preparación para la vida ciudadana no debían precipitarse los acontecimientos. Estaba consciente de que la sociedad existente no era la que debía ser; por tanto, se luchaba por crear las bases, los hombres que la hicieran posible.

Se enmarca en un reformismo evolutivo, según plantean Buenavilla et al. (1995), ya que luchaba por reformas con vistas a la plena independencia. Aunque no fue un hombre de acción revolucionaria, la desarrolló en el quehacer educacional, filosófico y en la polémica pública. Luchó contra los que querian aplicar la teoría ecléctica de Cousin, al tratar de imponer el integrismo sobre el cubanismo, de conservar la unidad nacional de Cuba por la de España.

Consideraba, por tanto, que el objetivo de la educación era formar hombres cultos, sinceros, patriotas y laboriosos. Con mucha razón expresó con claridad: "Instruir puede cualquiera, educar solo quien sea un evangelio vivo" (Luz, 1945, p. 73), por lo que enfatizó en la unidad indisoluble de la instrucción y la educación. Se esforzó por mantener el vínculo ideológico con el padre Varela a través de las Cartas a Elpidio, que los españoles trataban de cortar para impedir el nexo directo entre el pensamiento vareliano y la juventud criolla.

Luz Caballero empleó métodos productivos para enseñar y desarrollar la reflexión, el pensamiento y el razonamiento en los estudiantes. En las aulas de su colegio El Salvador se aplicaba el método de aprendizaje a partir de la duda, de la investigación, propugnó la necesidad del vínculo de la teoría con la práctica en la enseñanza e introdujo el método explicativo propuesto por Varela.

En su colegio se realizaban sistemáticamente las charlas sabatinas, lección de moral práctica; enseñó a preferir la justicia por encima del éxito y la fortuna, así educó un ardiente amor por la patria. Valoró el método del ejemplo como el primero y más eficaz de todas las costumbres educativas.

Realizó múltiples trabajos acerca de la educación en su larga vida magisterial. Teorizó sobre la importancia de la pedagogía, a la vez que efectuó loables intentos para materializar la formación de maestros, por lo que expresaria: "Tengamos el magisterio y Cuba será nuestra" (Luz, 1945, p. 74). Fue una figura controvertida, a pesar de su profundo patriotismo, "no llegó a compartir el ideario independentista, aunque supo formar a varias generaciones de cubanos al inculcarles el orgullo de la cubanía" (Quintana, 2007, p. 17).

Por su parte, la metrópolis se convenció de que mediante formas no escolarizadas de educación era imposible garantizar la formación de las nuevas generaciones, de acuerdo con los intereses clasistas que perseguía, pues ya desde finales de la década de 1830 se percibia la crisis del régimen esclavista. Por estas razones, se apresuró en la promulgación de disposiciones legales para establecer un sistema centralizado de educación en la colonia cubana.

Para ello, elaboró el plan de estudio de 1842, decretado como Ley de Instrucción Pública para la Isla de Cuba y la de Puerto Rico, puesta en vigor al siguiente año. Dispuso, además, el cese de las funciones oficiales ejercida por la Sociedad Económica en relación con la enseñanza y que esta quedase bajo la dirección y administración de una corporación creada por dicha ley, 
con el nombre de Inspección de Estudios. Su desaparición conllevó a una alarmante disminución de la actividad educacional en la Isla, con una sensible afectación para las capas populares. En ese año fue también secularizada la Universidad.

En la cuarta década del siglo xIx comenzó a desarrollar su labor magisterial Rafael María Mendive, el maestro del Apóstol, quien supo inculcar sentimientos patrióticos en sus alumnos desde la poesía y sus clases. "Los conceptos fundamentales en que descansa la prédica martiana: amor a la libertad, decoro, dignidad, prestigio, justicia, preocupación por los humildes, pureza de pensamiento, eran virtudes atesoradas por Mendive" (García, 1972).

Rafael María Mendive fue un educador excepcional, comprendió y alentó el amor que sentía por la patria su eminente discipulo, José Martí. En sus funciones como director de la Escuela Municipal de Varones y en su propio Colegio San Pablo, educó a través de la persuasión, el ejemplo y la rectitud, así como enseñó la importancia que tienen las letras y las ciencias en la formación del hombre.

Al estallar la Revolución de 1868, el Gobierno colonial español clausuró los colegios privados y dictó medidas para castigar a los educadores incorporados al Ejército Libertador, pero la lucha continuaba con mayor fuerza. Se celebró la Asamblea de Guáimaro y se redactó la primera Constitución cubana que reflejaba el aspecto educacional.

Se aprobó la Ley de Instrucción Pública de la República, propuesta por el maestro Rafael Morales González, Moralitos. Esta ley constituyó una respuesta revolucionaria al poder colonial al plantear el carácter gratuito, democrático y estatal de la educación, así como la obligatoriedad de la enseñanza de la historia y geografía de Cuba. Se fundaron las escuelitas de la retaguardia y circuló la cartilla de alfabetización creada por Moralitos para luchar contra el analfabetismo.

El combate bélico se extendió diez años aproximadamente, pero terminó con una paz sin independencia y sin abolición de la esclavitud, aspiraciones supremas por las que se lanzaron los cubanos a la lucha contra el yugo colonial español.

Es necesario señalar que de 1790 a 1878 se desarrolló el periodo de auge y crisis del régimen esclavista en la Isla. Resulta indiscutible que la clase social que se encontraba en el centro de esta etapa era la burguesía cubana, cuyo desarrollo económico e ideológico ascendente constituyó la principal fuerza motriz del posible progreso histórico. Desde el punto de vista político-ideológico, asumieron diversas actitudes que fluctuaron entre el reformismo y el independentismo. Al terminar la guerra, esta clase social retomó el reformismo, considerado como opción aún viable a la solución del problema nacional cubano.

Sin embargo, el ideal independentista estuvo vigente en estos años y, en 1895, se inició la guerra de independencia preparada por José Martí, quien también ocupa un lugar sobresaliente en la historia de la educación cubana. La huella de su enseñanza trascendió los marcos académicos al enseñar con la pluma y el fusil. De ahí que su obra quedara grabada como ninguna otra en las posteriores generaciones de cubanos y, especialmente, en la que se dedicó a continuar su ideal de lucha por la emancipación social.

Se coincide con que es José Martí "punto culminante, radical y orgánico del pensamiento educacional y pedagógico cubano del siglo xIx" (Buenavilla et al., 1995), ya que en sus artículos periodísticos, escritos en los Estados Unidos y en América Latina, se encierra su pensamiento pedagógico, que constituye un preciado legado y es parte esencial de la historia de la educación en Cuba.

No pueden obviarse las cartas a María Mantilla que son verdaderas recomendaciones didácticas. Particular importancia reviste su carta del 9 de abril de 1895, escrita desde Cabo Haitiano, considerada como su testamento pedagógico, donde le inculca el amor por el magisterio. Le dijo a la niña con gran ternura:

[...] enseñar es crecer [...] estudia mi Maria, trabaja, y espérame [...] aprende de mí. Tengo la vida a un lado de la mesa y la muerte a otro, y un pueblo a las espaldas [...]. Así serán maestras, contando esos cuentos verdaderos a sus discipulas [...]. Que las discípulas amen la escuela, y aprendan en ella cosas agradables y útiles [...]. (Martí, 2001, pp. 34-39)

José Martí integró de manera orgánica sus concepciones filosóficas, políticas, axiológicas y pedagógicas acerca de la labor del maestro. En todo su pensamiento está presente el papel que desempeña 
en la formación moral, así como la unidad de la instrucción y la educación.

Instrucción no es lo mismo que educación: aquella se refiere al pensamiento y ésta precisamente a los sentimientos. Sin embargo, no hay buena educación sin instrucción, las cualidades morales suben de precio cuando están realizadas por las cualidades inteligentes. (Martí, 1963, p. 90)

Asimismo, consideró que, en el proceso formativo del hombre, el maestro no debe de ninguna manera "rebajar las aspiraciones delicadas, superiores y espirituales de la mejor parte del ser humano", y además formarlos, "a nuestros niños se les debe criar para hombres de su tiempo y hombres de América" (Martí, 1963, p. 91).

El Apóstol de la independencia de Cuba trazó importantes propuestas para la educación en los países latinoamericanos y en Cuba. Expuso con precisión las necesidades educativas que clamaba su patria: educación laica, educación científica y politécnica; educación para la vida; educación nacionalista; escuela primaria; el contenido de la educación debía ser democrático y popular; incorporación de la mujer a la educación; lucha contra el analfabetismo.

Esta educación debía propiciar la formación de un hombre nuevo: libre, integral, multifacético, crítico, con valores morales elevados, con opiniones propias, capaz de crear y defender una sociedad con todos y para el bien de todos, como reafirmaría en un memorable discurso años más tarde: "Hombres vivos, hombres directos, hombres independientes, hombres amantes, eso han de hacer las escuelas, que ahora no hacen eso" (Martí, 1963, p. 93).

\section{Conclusiones}

» Entre 1790 y 1898, un sector de la burguesía nacional criticó duramente el sistema educativo hispano-escolástico y el proyecto político que lo sostenía, así como creó su ideario educativo conveniente a sus intereses clasistas con el fin de lograr los cambios necesarios en la sociedad colonial imperante.
»En el periodo histórico colonial, el alcance social de la educación tuvo en Félix Varela un importante precursor con el origen del concepto de educación popular y encuentra en José Martí la más elevada expresión.

» Las ideas educativas evolucionaron desde la ilustración y el positivismo crítico, hasta llegar al avanzado pensamiento pedagógico de Martí.

"La aplicación de las ideas educativas cubanas tuvo como resultado la formación de la conciencia de la cubanía. Esas ideas estaban encaminadas a la formación del hombre cubano, cuyos principales valores estuvieron centrados en la idea de la libertad y la independencia nacional.

» Se puede afirmar que, de Caballero a Varela, de Varela a Luz Caballero, de Luz a Rafael María de Mendive, de Mendive a José Martí, está la escalera que peldaño a peldaño asciende a la cúspide del pensamiento fundacional cubano. Con esas ideas se formaron hombres, hombres capaces de construir una nación.

\section{Referencias}

Azel, J. (2018). Vida y obra educativa de Margot Machado Padrón (Tesis doctoral no publicada). Universidad Central Marta Abreu de Las Villas. Santa Clara, Cuba.

Azel, J., y Pérez, R. (2018). Saco, Varela, Céspedes: Ios principales iniciadores de la nacionalidad y la nación cubanas. Santa Clara, Cuba: Editorial Feijóo.

Buenavilla, R., Cartaya, P., Joanes, J., Silverio, M., Santos, N., Martínez, M., Benítez, J., Orille, L., y Echevarría, I. (1995). Historia de la pedagogía en Cuba. La Habana: Editorial Pueblo y Educación.

García, G. (1972). Maestros. La Habana: Editorial Pueblo y Educación.

Luz, J. (1945). Aforismos. La Habana: Editorial de la Universidad de La Habana.

Martí, J. (1963). Obras completas [tomos 15 y 19]. La Habana: Editorial Imprenta Nacional de Cuba.

Martí, J. (2001). Cartas a María Mantilla. La Habana: Editorial Gente Nueva.

Pérez, R. (2007) Estudio de la obra educativa de José Agustín Caballero como iniciador de la Pedagogía cubana. (Tesis doctoral no publicada). Instituto Superior Pedagógico Félix Varela. Santa Clara, Cuba. 


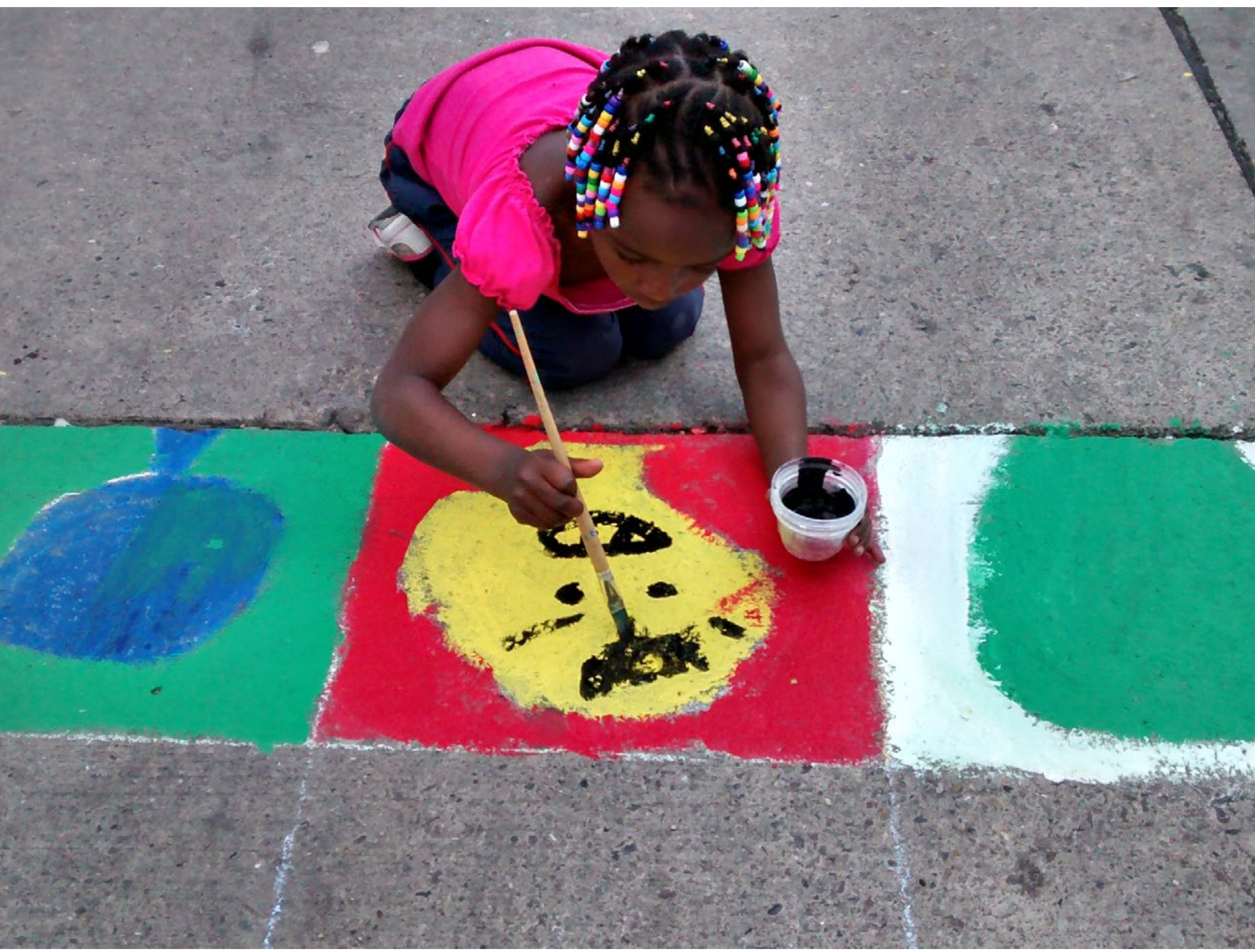


Quintana, R. (2007). Significación del ideario educativo de Fidel Castro en la formación de maestros primarios y profesores de la enseñanza media en la Cuba revolucionaria (Tesis doctoral no publicada). Instituto Superior Pedagógico Enrique José Varona. La Habana, Cuba.

Sánchez, N. (2019). Prácticas etnoeducativas en el departamento de Chocó: desafíos para una educación pertinente con la realidad y la vida. Nodos y Nudos, 6(45), 96-103.
Torres-Cuevas, E. (2017). Espada y escudo de la nación cubana. La Habana: Cubadebate.

Torres-Cuevas, E., y Loyola, O. (2006). Historia de Cuba 14921899. Formación y liberación de la nación. La Habana: Editorial Pueblo y Educación.

Varela, F. (1935). Educación y patriotismo. La Habana: Editorial Secretaría de Educación, Dirección de Cultura.

\section{Diálogo del conocimiento}

El tema de la identidad nacional ha sido objeto de grandes debates en el mundo académico. En paises en los que el Estado precedió a la nación, en los que incluso la consolidación de un Estado nacional continúa siendo aún hoy una tarea pendiente, el asunto de la identidad nacional resulta algo crucial para la definición de los destinos comunes. $Y$ en sociedades caracterizadas por una gran diversidad étnica y cultural el tema adquiere mayor complejidad, al punto en que algunos prefieren el empleo del plural para referirse a ese entramado de identificaciones al que concurren lo local, lo nacional, lo global, lo étnico, el género y lo generacional, lo que hace difícil la caracterización de los referentes identitarios.

Lo anterior viene a colación a raiz del interesante rastreo del papel de las ideas sobre la educación que pueden estar presentes en la configuración de la "cubanía", concepto que en el artículo no se encuentra definido ni su contenido se alcanza a descifrar del todo. "Cubania" o "cubanidad" aludirian a unas formas particulares de ser y de pensar de los cubanos, formas idiosincráticas que recibieron el influjo de los pensadores cubanos que propusieron ideas sobre la educación en distintos momentos de la historia. Muchas de esas ideas provienen de la ilustración y son las mismas que orientaron a las revoluciones burguesas y a las guerras de independencia de las colonias españolas en América en el siglo XIX. Ideas con las que se configuró la modernidad, y que se complementaron con el liberalismo económico, la democracia política y el positivismo científico. La pregunta que surge es por las especificidades de la cubania que la hacen diferente del patriotismo y los sentimientos independentistas comunes a todos los países de América Latina, nacidos de los procesos que reclamaban libertad, independencia y soberanía nacional con respecto al poder colonial. ¿Habría algunas caracteristicas de lo cubano que establecerian rasgos distintivos y diferenciadores de lo propio de otras nacionalidades? Seguramente que si, aunque no se logra colegir de las ideas educativas mencionadas en el texto, dada su inscripción en el ideario demoliberal de la burguesia revolucionaria decimonónica. Quizás en la idea de educación popular presente en esta pesquisa se encuentre un yacimiento para futuras exploraciones.

Juan Francisco Aguilar Soto

Universidad Pedagógica Nacional 